\title{
How Do Layoff Costs Affect Employment?
}

\author{
by \\ Lars Ljungqvist \\ Stockholm School of Economics and CEPR
}

August 1999

General equilibrium analyses of layoff costs have had mixed messages on the implications for employment. This paper brings out the economic forces at work in different frameworks and explains the disparate results. Since private agents perceive layoff costs as equivalent to a less productive technology, these costs tend to have negative employment effects in models with employment lotteries where the number of employed can be reduced at a low cost to individual agents because of the collective sharing of aggregate consumption. In search models where agents are left to fend for themselves, layoff costs have the opposite tendency of lowering unemployment when such costs reduce the amount of labor reallocation. Lower frictional unemployment is thus attained at the cost of a less efficient labor allocation. Matching models have this very same tendency under the assumption that layoff costs do not alter the relative split of the match surplus between firms and workers. In contrast, if layoff costs increase workers' relative share of the surplus, matching models tend to post sharp increases in unemployment in response to layoff costs.

JEL-Classification: E24, J63, J68

Keywords: Layoff costs, unemployment

* Address: Stockholm School of Economics, Box 6501, SE-113 83 Stockholm, Sweden, phone +4687369209, email lars.ljungqvist@hhs.se

I have benefited from comments in seminars at MacMaster University, the Federal Reserve Bank of Chicago, the Summer Workshop in Macroeconomics at Northwestern University, the European University Institute, the Chinese University of Hong Kong, University College London and Tinbergen Institute, and I would especially like to thank Fernando Alvarez, Ed Prescott and Nancy Stokey. Tatiana Damjanovic provided excellent research assistance. 


\section{Introduction}

A common concern is that labor market rigidities such as layoff costs are responsible for high European unemployment (see e.g. OECD (1994)). As documented by Emerson (1988) and Lazear (1990), layoff costs are particularly burdensome in Europe. This paper explores a few general equilibrium models to see what kind of relationship there is between layoff costs and an economy's level of employment. The analysis focuses solely on layoff costs in isolation from other European labor market policies that might also influence unemployment rates such as minimum wages and generous unemployment compensation.

Layoff costs have been shown to have ambiguous employment effects in partial equilibrium analyses (see Bentolila and Bertola (1990), and Bertola (1990)). Layoff costs reduce both firms' hiring rates and firing rates. The cyclical implications are therefore fairly clear; layoff costs increase employment in troughs and reduce employment in peaks. But it is unclear what the effects are on the average employment level. Bentolila and Bertola find in their model that layoff costs actually increase average employment since the fact that they prevent layoffs dominates the effect from lower hiring. The question is whether or not this result is born out in a general equilibrium.

Early general equilibrium analyses by Burda (1992), Hopenhayn and Rogerson (1993), and Saint-Paul (1995) suggest that layoff costs affect employment negatively. They reach the same result but in quite different models of employment determination. However, later general equilibrium models by Alvarez and Veracierto (1997), and Mortensen and Pissarides (1997) display positive employment effects of layoff costs. Our paper examines the economic forces at work in these various analyses and explain the disparate results. We contrast three alternative frameworks of employment determination; a search model, a matching model and a model with employment lotteries. By studying bare-bones versions of these models, we are able to highlight the central mechanisms determining the employment implications of layoff costs.

To shed light on Hopenhayn and Rogerson's (1993) conclusion that layoff costs reduce equilibrium employment, we abstract from the elaborate firm size dynamics of their model and focus on employment lotteries as the sole important feature of their analysis. Since the private economy perceives layoff costs as equivalent to a less productive technology, 
these costs induce households to choose a lower probability of working in the lotteries over employment. This outcome is a manifestation of the well-known high elasticity of labor supply in models with employment lotteries. In contrast, a standard search model tends to produce the opposite result, i.e., the unemployment rate falls with higher layoff costs. The explanation is that layoff costs slow down the reallocation of labor, and thereby reduce the rate of frictional unemployment. This effect of labor being "locked into" their current employment drives the lower unemployment rate in Alvarez and Veracierto's (1997) analysis of layoff costs. Their auxiliary assumptions on risk aversion and incomplete markets are not essential for the employment outcome (but do matter for the welfare implications).

In the case of the matching model, the effects of layoff costs depend upon the specific assumption on how these costs affect the bargaining game between firms and workers. When using Saint-Paul's (1995) assumption that layoff costs increase workers' relative share of the match surplus, the model reproduces his result that layoff costs increase the unemployment rate. The reason is that firms' profitability must then be restored in an equilibrium through a shorter expected time to fill a vacancy, i.e., there has to be a larger number of unemployed workers for each posted vacancy. In contrast, if layoff costs do not alter the relative split of the match surplus between firms and workers, the employment effect is the same as in the search model where higher layoff costs reduce the rate of unemployment. Once again, the dominating effect is that layoff costs diminish the value of reallocating labor so that job tenures lengthen and unemployment falls.

The last explanation applies also to Mortensen and Pissarides' (1997) matching model with a two-tier wage system such that layoff taxes do not affect the relative split of the match surplus when firms bargain with not yet hired workers, while these costs do increase the relative surplus share of hired workers in consecutive renegotiations. We demonstrate that their specification is formally equivalent to our second assumption that the relative split of the match surplus is unaffected throughout the employment relationship. The only difference between the two formulations is that the wage profile in the Mortensen and Pissarides' setting is tantamount to new workers posting a bond equal to their share of any future layoff tax.

A prerequisite for layoff costs to reduce unemployment in the search model and the 
matching with a constant relative split of the match surplus is that the production technology allows for an endogenous lengthening of job tenures. Burda's (1992) finding that layoff costs unambiguously increase unemployment in a matching model follows from his assumption of an exogenous rate of job destruction. We use such counterexamples with extreme parameterizations to further shed light on the workings of the different models.

The next section describes the production technology and the government's policy of imposing a layoff tax for each job that is destroyed. These assumptions are maintained throughout the paper, and they capture the essential features of the general equilibrium analyses of layoff costs in the literature. Section 3 presents our three different models of employment determination, which are bare-bones versions of the models in the literature in order to highlight their central mechanisms in the most transparent way. Numerical simulations and robustness tests are utilized in Section 4 to shed light on the employment effects of layoff taxes. Section 5 provides a discussion of the economic forces at work while the final section offers a few concluding comments.

\section{Technology and Government Policy}

A very simple technology will be useful to bring out the employment implications of layoff costs in different models. An agent is either unemployed in period $t, n_{t}=0$, or full-time employed, $n_{t}=1 .^{1}$ The productivity of a new job is equal to $p^{o}$, and the future productivity level follows a Markov process given by the distribution function $G\left(p, p^{\prime}\right)=$ $\operatorname{Prob}\left(p_{t+1} \leq p^{\prime} \mid p_{t}=p\right)$ which is decreasing in $p$. The job disappears when there is no worker assigned to the job. The productivity level is observed at the beginning of a period before the decision whether or not to retain the job is made.

The government imposes a tax $\tau \geq 0$ for each job that is destroyed. The tax revenues, denoted $T$ per capita, are handed back lump-sum to the agents. By abstracting from distortionary transfer policies and other kind of taxes, we can isolate the employment effects due to layoff costs. These assumptions on government policy and technology capture the essential features of the general equilibrium analyses of layoff costs in the literature.

\footnotetext{
1 The assumption of only full-time jobs is innocuous in the search model and the matching model, but it is a key element in the model with employment lotteries.
} 


\section{Alternative Models of Employment Determination}

We consider three alternative models of employment determination; a search model, a matching model and a model with employment lotteries. We study stationary equilibria when each model is populated by a continuum of infinitely lived workers of measure one.

First, in the spirit of Stigler (1961) and McCall (1970), we will assume that workers must search for new jobs. Unemployed workers choose an optimal search intensity, which will influence the average length of unemployment spells. Taking the search costs into account, employed workers will in turn have to decide on an optimal reservation productivity. For realizations of the productivity level greater than or equal to the reservation productivity, they remain on the job, and otherwise they leave to search for another job.

Second, we will examine a matching model along the lines of Diamond (1982), Mortensen (1982) and Pissarides (1985). The number of vacancies and unemployed workers enter as arguments in a matching function to determine the number of successful matches in any given period. The surplus associated with a match is split between the worker and the firm through Nash bargaining. We will explore the implications of two different bargaining assumptions: a) the worker's relative share of the match surplus stays constant when varying the layoff cost, b) the worker's relative share increases with the layoff cost. In an equilibrium, the number of vacancies is such that the expected discounted profit associated with posting a vacancy is zero.

Third, we will follow the approach taken in Hopenhayn and Rogerson's (1993) analysis of layoff costs, in which variations in the employment level is driven by optimal changes in employment lotteries. In their framework, workers and jobs can be matched without any frictions. But the restriction that all jobs must be full-time is binding and, thus, it is welfare enhancing to introduce employment lotteries as in Hansen (1985) and Rogerson (1988). In each period, agents are assumed to choose a probability of working instead of the number of hours to work. A lottery then determines which agents actually work. The choice of probabilities and the outcome of the lottery are assumed to be public information, so that insurance markets are fully operational for the idiosyncratic risk associated with the lottery. Firms create new jobs as long as the expected discounted profits are nonnegative. 


\subsection{Search model}

An unemployed worker chooses a search intensity $s \geq 0$ at a disutility of $\gamma(s)$ which is increasing in $s$. With probability $\pi(s)$, the unemployed worker finds a new job at the beginning of next period. We assume that $\pi(s) \in[0,1]$, and that it is increasing in $s$. The agents are assumed to be risk-neutral with preferences given by

$$
E_{0} \sum_{t=0}^{\infty} \beta^{t}\left[c_{t}-A_{s} n_{t}-\gamma\left(s_{t}\right)\right],
$$

where $E_{0}$ is the expectation operator conditional upon information at time 0 and $\beta \in(0,1)$ is a discount factor. The agent's consumption and employment in period $t$ are denoted $c_{t} \geq 0$ and $n_{t} \in\{0,1\}$, respectively. An agent suffers disutility $A_{s}>0$ when working.

Under the assumption of risk neutrality, each worker can be treated as self-employed and liable for any layoff tax. Let $V(p)$ be the value of the optimization problem for an employed worker with productivity $p$ at the beginning of a period. The value associated with being unemployed is $V_{u}$. Bellman's equations can then be written as follows.

$$
\begin{aligned}
V(p) & =\max _{\text {work, layoff }}\left\{p-A_{s}+T+\beta \int V\left(p^{\prime}\right) d G\left(p, p^{\prime}\right), V_{u}-\tau\right\}, \\
V_{u} & =\max _{s}\left\{-\gamma(s)+T+\beta\left[(1-\pi(s)) V_{u}+\pi(s) V\left(p^{o}\right)\right]\right\} .
\end{aligned}
$$

Associated with the solution of equations (2) and (3) will be two numbers $(\bar{s}, \bar{p})$ giving an optimal search intensity of an unemployed worker and a reservation productivity of an employed worker.

Given this formulation with self-employed workers and no other assets in the economy, the expected life-time utility of an employed worker with productivity $p$ is given by $V(p)$, and the welfare of an unemployed worker is equal to $V_{u} \cdot{ }^{2}$

\footnotetext{
2 The aggregate implications of the model would be the same, if we instead let a 'firm' or a financial intermediary offer the following employment contract to a worker who has found a job opportunity. The firm and the worker commit themselves to sustain an employment relationship with a fixed wage $\hat{w}$ as long as the productivity of the job is greater than or equal to $\bar{p}$, and the firm assumes liability for any layoff tax. The equilibrium value of $\hat{w}$ would be such that firms break even, i.e., the expected discounted value of the job's all future $p-\hat{w}$ is equal to the expected discounted value of the eventual layoff tax. In this alternative formulation, the expected welfare of an individual is unchanged but the calculations would involve payment flows arising from firm ownership as in the matching model and the model with employment lotteries below.
} 


\subsection{Matching model}

The preference specification for the matching model is the same as for the search model except that we drop the disutility of searching,

$$
E_{0} \sum_{t=0}^{\infty} \beta^{t}\left[c_{t}-A_{m} n_{t}\right] .
$$

The cost of posting a vacancy is $\kappa$ per period. The number of successful matches is given by a linearly homogeneous matching function $M(u, v)$, where $u$ and $v$ are the measures of unemployed workers and vacancies, respectively.

Let $Z(p)$ be the match surplus associated with a productivity level $p$, i.e., the expected discounted value of the match in excess of the worker's outside option $Z_{u}$. For a given $Z_{u}$, the Bellman's equation can be written as $^{3}$

$$
Z(p)+Z_{u}=\max _{\text {work, layoff }}\left\{p-A_{m}+\beta \int\left[Z\left(p^{\prime}\right)+Z_{u}\right] d G\left(p, p^{\prime}\right), Z_{u}-\tau\right\}
$$

Associated with the solution of equation (5) is a number $\bar{p}$ giving a reservation productivity of a match.

A standard approach in the matching literature is to assume that the match surplus is split between the worker and the firm through Nash bargaining. Let $F(p)$ and $W(p)$ denote the firm's and the worker's expected discounted value in a match with productivity level $p$, where $W(p)$ includes the worker's continuation value $Z_{u}$. That is, the following identity holds

$$
Z(p)=F(p)+W(p)-Z_{u}
$$

The firm's and the worker's shares of the match surplus are then set so as to maximize a Nash product. Here we will explore the implications of two alternative specifications of the Nash product:

$$
\begin{aligned}
& \left(W(p)-Z_{u}\right)^{\delta} F(p)^{1-\delta}, \\
& \left(W(p)-Z_{u}\right)^{\delta}(F(p)+\tau)^{1-\delta} .
\end{aligned}
$$

\footnotetext{
3 Note that the match surplus and the worker's outside option do not include any earnings of the worker which are independent of the match such as the lump-sum transfer from the government, $T$, and any asset earnings.
} 
Specification (7.a) leads to the usual result that the worker receives a fraction $\delta$ of the match surplus, while the firm gets the remaining fraction $(1-\delta)$;

$$
W(p)-Z_{u}=\delta Z(p) \quad \text { and } \quad F(p)=(1-\delta) Z(p)
$$

The alternative specification (7.b) adopts the assumption of Saint-Paul (1995) that the layoff cost changes the firm's threat point from 0 to $-\tau$, and thereby increases the worker's relative share of the match surplus. Solving for the sharing rules yields:

$$
W(p)-Z_{u}=\delta(Z(p)+\tau) \quad \text { and } \quad F(p)=(1-\delta) Z(p)-\delta \tau
$$

Mortensen and Pissarides (1997) propose still another bargaining specification where (7.a) is the Nash product when a worker and a firm meet for the first time, while the Nash product in (7.b) characterizes all their consecutive renegotiations. The idea is that the firm will not incur any layoff tax if the firm and worker do not agree upon a wage in the first encounter because there is never an employment relationship. In contrast, the firm's threat point is weakened in future negotiations with an already employed worker since the firm would then have to pay a layoff tax if the match is broken up. Except for the wage profile, the appendix demonstrates that this alternative specification is equivalent to just assuming (7.a) for all periods. The intuition is that the modified wage profile under the Mortensen and Pissarides' assumption is tantamount to a new hire posting a bond equal to his share of the future layoff tax. It is therefore sufficient to here focus on the first two bargaining specifications.

The worker's continuation value outside of the match, $Z_{u}$, is the expected discounted value of an unemployed worker, which in turn depends on the bargaining game between workers and firms. The two alternative expressions for $Z_{u}$ associated with Nash product (7.a) and (7.b), respectively, are

$$
\begin{aligned}
& Z_{u}=\beta\left[\frac{M(u, v)}{u}\left(\delta Z\left(p^{o}\right)+Z_{u}\right)+\left(1-\frac{M(u, v)}{u}\right) Z_{u}\right], \\
& Z_{u}=\beta\left[\frac{M(u, v)}{u}\left(\delta\left[Z\left(p^{o}\right)+\tau\right]+Z_{u}\right)+\left(1-\frac{M(u, v)}{u}\right) Z_{u}\right] .
\end{aligned}
$$

The expressions capture the two possible outcomes in the next period; the unemployed worker either finds a job or continues to look for one. The remaining equilibrium condition 
that firms post vacancies until the expected profits are driven down to zero can be expressed as follows for Nash products (7.a) and (7.b), respectively,

$$
\begin{aligned}
\frac{M(u, v)}{v}(1-\delta) Z\left(p^{o}\right) & =\kappa, \\
\frac{M(u, v)}{v}\left[(1-\delta) Z\left(p^{o}\right)-\delta \tau\right] & =\kappa .
\end{aligned}
$$

In order to do welfare calculations in the matching model, we need to compute profit flows from firms. In a stationary equilibrium, let $H(p)$ be the fraction of all filled jobs with a productivity less than or equal to $p$. Since $\bar{p}$ is the reservation productivity, we have $H(\bar{p})=0$. A job with productivity $p$ generates a current profit of $p-w(p)$ where $w(p)$ is the wage rate determined in the described Nash bargaining. The profit can then be deduced from the equilibrium function for the firm's share of the match surplus,

$$
p-w(p)=F(p)-\beta \int F\left(p^{\prime}\right) d G\left(p, p^{\prime}\right)
$$

Among all jobs with a current productivity of $p$, there will be a fraction $G(p, \bar{p})$ that shuts down next period with a layoff tax of $\tau$ per destroyed job. The firm is solely liable for the layoff tax under Nash product (7.b) but it only pays a share $1-\delta$ under Nash product (7.a). Firms posting vacancies generate a profit of $-\kappa$ per vacancy and period. In all, the aggregate profits from firms in any given period are as follows for Nash products (7.a) and (7.b), respectively,

$$
\begin{aligned}
& \Pi=(1-u) \int[p-w(p)-(1-\delta) \tau G(p, \bar{p})] d H(p)-\kappa v, \\
& \Pi=(1-u) \int[p-w(p)-\tau G(p, \bar{p})] d H(p)-\kappa v,
\end{aligned}
$$

where $(1-u)$ and $v$ are the equilibrium measures of filled jobs and vacancies.

A stationary equilibrium is consistent with any arbitrary distribution of firm ownership among the workers. The asset value of each firm is such that its expected gross rate of return is equal to $1 / \beta$, and the economy's aggregate assets generate the same but deterministic rate of return. Let us here assume that all workers own identical shares 
of the economy's total assets. The expected life-time utility of an employed worker with productivity $p$ is then given by

$$
W(p)+\sum_{t=0}^{\infty} \beta^{t}[\Pi+T],
$$

where the lump-sum transfer from the government, $T$, is just equal to the per capita value of all paid layoff taxes. By replacing $W(p)$ by $Z_{u}$, the expression shows the welfare of an unemployed worker.

\subsection{Model with employment lotteries}

The linear preferences in the two previous models do not leave any room for welfareimproving employment lotteries. We therefore introduce curvature on the consumption term. As in Hopenhayn and Rogerson (1993), we postulate the following preferences

$$
E_{0} \sum_{t=0}^{\infty} \beta^{t}\left[u\left(c_{t}\right)-v\left(n_{t}\right)\right],
$$

where $v(0)=0$ and $v(1)=A_{l}$. All agents are identical and have access to markets to insure against the idiosyncratic risk associated with employment lotteries. This implies that the economy behaves as though there were a representative agent with preferences defined by

$$
E_{0} \sum_{t=0}^{\infty} \beta^{t}\left[u\left(c_{t}\right)-A_{l} N_{t}\right],
$$

where $N_{t}$ is the fraction of agents who are working in period $t$.

Firms and workers meet without any frictions in a Walrasian labor market. In a stationary equilibrium with the gross interest rate equal to $1 / \beta$, the equilibrium wage rate is determined from the demand side for labor as follows. Consider a firm that maximizes expected discounted profits and takes the wage $w$ as given. Let $X(p ; w)$ be the firm's value of a job with productivity $p$. The Bellman's equation can then be written as

$$
X(p ; w)=\max _{\text {work, layoff }}\left\{p-w+\beta \int X\left(p^{\prime} ; w\right) d G\left(p, p^{\prime}\right),-\tau\right\} .
$$

Associated with the solution of equation (14) is a reservation productivity $\bar{p}$. The equilibrium wage $w^{*}$ must be such that expected profits associated with new jobs are zero, i.e., $X\left(p^{o} ; w^{*}\right)=0$. 
As noted by Hopenhayn and Rogerson (1993), another implication of a stationary equilibrium is that the representative agent's optimization problem reduces to a static problem of the form,

$$
\max _{N} u(c)-A_{l} N \quad \text { subject to } c \leq w^{*} N+\Pi+T,
$$

where the profits from firms, $\Pi$, and the lump-sum transfer from the government, $T$, are taken as given by the agents. In a stationary equilibrium with $\left(w^{*}, N^{*}\right)$, we have

$$
\Pi+T=N^{*} \int\left[p-w^{*}\right] d H(p),
$$

where $H(p)$ is once again the fraction of all jobs in a stationary equilibrium with a productivity less than or equal to $p$. Since all agents are identical including their asset holdings, the expected life-time utility of an agent before seeing the outcome of the employment lottery is equal to

$$
\sum_{t=0}^{\infty} \beta^{t}\left[u\left(N^{*} \int p d H(p)\right)-A_{l} N^{*}\right]
$$

\section{Numerical Examples}

\subsection{Calibration}

The model period is chosen to be two weeks. We set the discount factor $\beta=0.9985$, making the annual interest rate 4.0 percent. Productivity levels are confined to the unit interval (with a grid size of 500 points), and the productivity of a new job is $p^{0}=0.75$. The Markov process for the future productivity level is constructed as follows. With probability 0.96 , the productivity will be the same as in the previous period, and, with probability 0.04 , the productivity is drawn from a distribution $\tilde{G}\left(p, p^{\prime}\right)$. That is, the worker will on average draw a new productivity level once a year. The distribution function $\tilde{G}\left(p, p^{\prime}\right)$ for the new productivity level $p^{\prime}$ is given by a normal distribution with a mean equal to the previous productivity level $p$ and a variance of 0.01 , which is truncated to the unit interval and normalized to integrate to one. 
Additional parameter values for the search model are as follows. The disutility from searching and the function mapping search intensities into probabilities of obtaining a wage offer are assumed to be

$$
\begin{aligned}
& \gamma(s)=0.5 s, \\
& \pi(s)=0.2 s^{0.3}, \quad \text { where } s \in[0,1],
\end{aligned}
$$

with a grid size of 1000 points for the search intensity s. These parameter values are the same as in Ljungqvist and Sargent (1998), except that we have multiplicatively scaled down the probability of finding a job to offset the present assumption that all new jobs offer wage $p^{o}$ which will always be acceptable in an equilibrium with production. The disutility from work, $A_{s}$, is set equal to 0.5 .

In the matching model, we keep the same parameter value of the disutility from work, $A_{m}=0.5$. The cost per period of posting a vacancy is $c=0.2$, and the matching function is assumed to be

$$
M(u, v)=\phi u^{\alpha} v^{1-\alpha}=0.01 u^{0.5} v^{0.5}
$$

The Cobb-Douglas form and a match elasticity with respect to unemployment, $\alpha$, of around 0.5 are common in the matching literature, and so is our next assumption that the worker's bargaining strength, $\delta$, is equal to $\alpha .{ }^{4}$ (See e.g. Pissarides and Mortensen, 1997.)

Following Hopenhayn and Rogerson (1993), the preference specification in the model with employment lotteries is $u(c)=\log (c)$ and the disutility of work is calibrated to match an employment to population ratio equal to 0.6 which leads us to choose $A_{l}=1.6$.

The simulations based on these parameter values are followed by a sensitivity analysis. The qualitative results are then found to be robust to perturbations of plus and minus 50 percent in all dimensions of the benchmark parameterization.

\footnotetext{
4 In the case of no layoff costs, Hosios (1989) shows that the matching process is efficient when the workers' share of the match surplus, $\delta$, and the match elasticity with respect to unemployment, $\alpha$, are equal.
} 


\subsection{Simulation results}

We compute stationary equilibria for different values of the layoff cost, $\tau \in[0,30]$. As a point of reference, $\tau=20$ corresponds to a layoff cost roughly equal to one year of an average worker's output. In each figure, there are curves referring to the search model ('S'), the model with employment lotteries ('L'), and the two versions of the matching model where the workers' relative share of the match surplus is either constant ('Ma') or positively related to the layoff cost ('Mb').

Figures 1 through 7 display a number of similarities across the different frameworks. A higher layoff cost is associated with a lower reservation productivity in figure 1 . That is, firms choose to retain workers with lower productivity when it becomes more costly to lay them off. As a consequence, figure 2 shows how layoffs as a fraction of employment falls with higher layoff costs but, according to figure 3, total layoff costs as a fraction of GNP is still increasing in $\tau$. Figure 4 reveals changing fortunes for the unemployed. A higher layoff cost reduces the probability of finding a job. This maps directly into a lower probability of working in the model with employment lotteries, while the same aspect manifests itself in the search model and the matching model as a lower probability of finding a job within, let say, 10 weeks of unemployment. Figures 5 and 6 show that the models also share a negative impact on welfare of higher layoff costs. The welfare losses are especially large in the matching model where workers' relative share of the match surplus is positively related to the layoff tax. The explanation can be found in figure 4 where that model is associated with a sharply falling probability of finding a job in response to a higher layoff tax. The effects on GNP are reported in figure 7 .

In contrast to these qualitative similarities across frameworks, a stark difference appears in figure 8. Employment increases with higher layoff costs in the search model and the matching model with a constant relative split of the match surplus, while the opposite is true in the two other models. We next demonstrate that these employment effects are robust to large perturbations in parameter values, before turning to a discussion of the economic forces at work. 


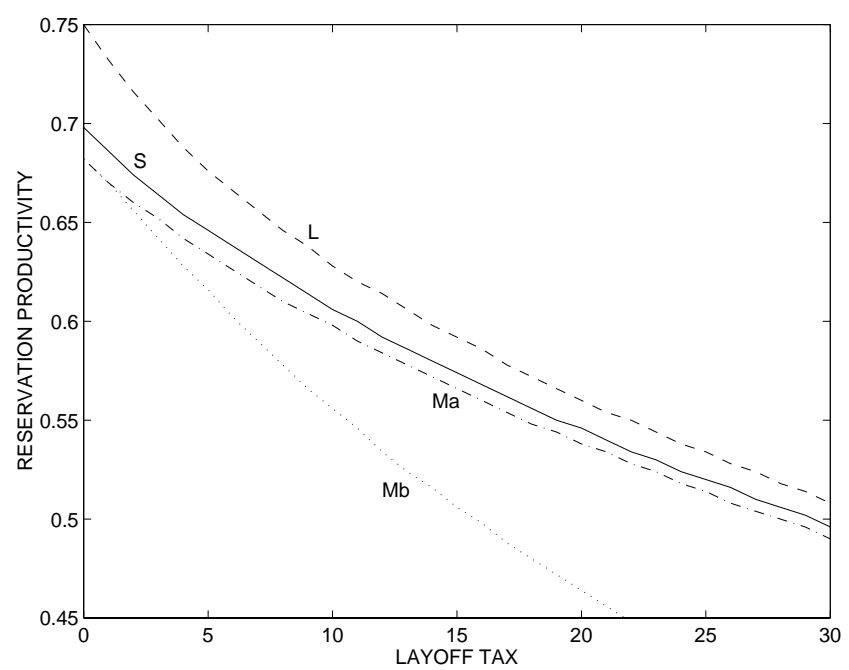

Figure 1. Reservation productivity for different values of the layoff tax.

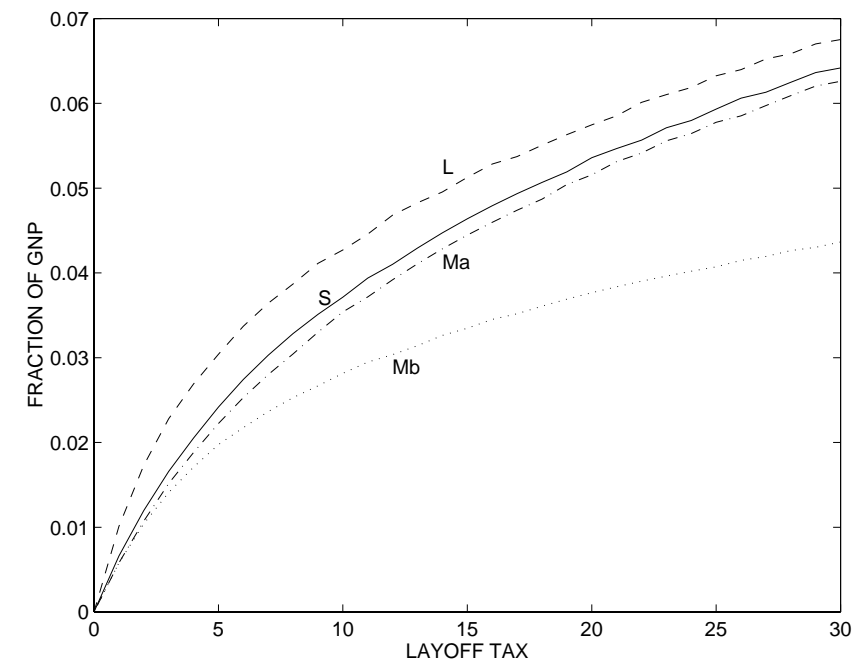

Figure 3. Layoff costs as a fraction of GNP for different values of the layoff tax.

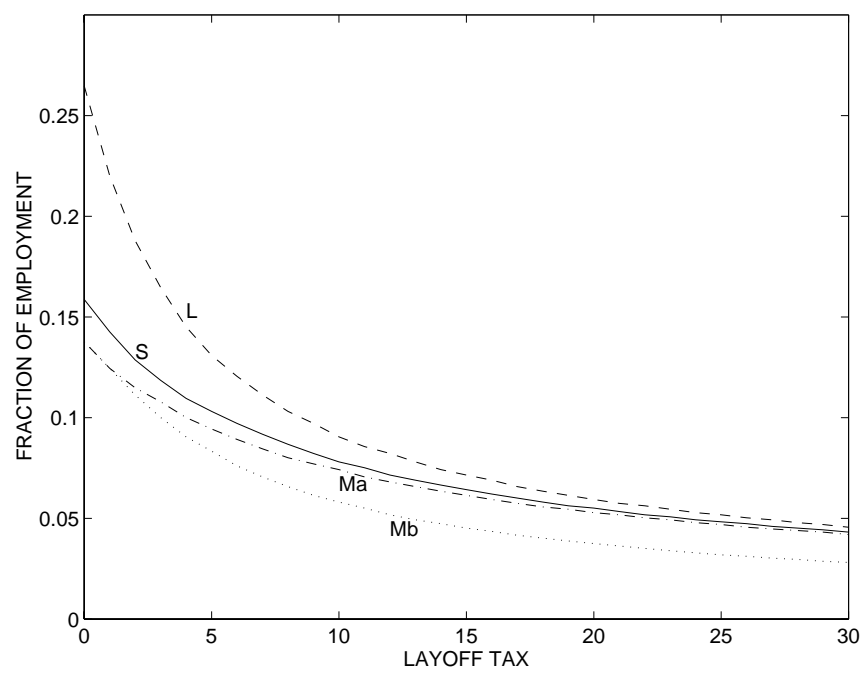

Figure 2. Annual layoffs as a fraction of employment for different values of the layoff tax.

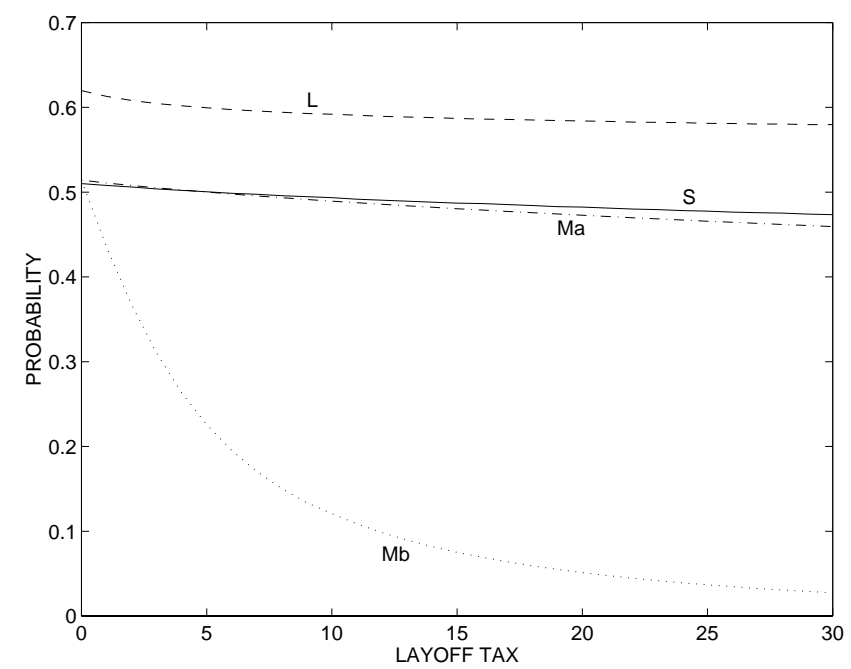

Figure 4. Probability of working in the model with employment lotteries and probability of finding a job within 10 weeks in the search model and the matching models, for different values of the layoff tax. 


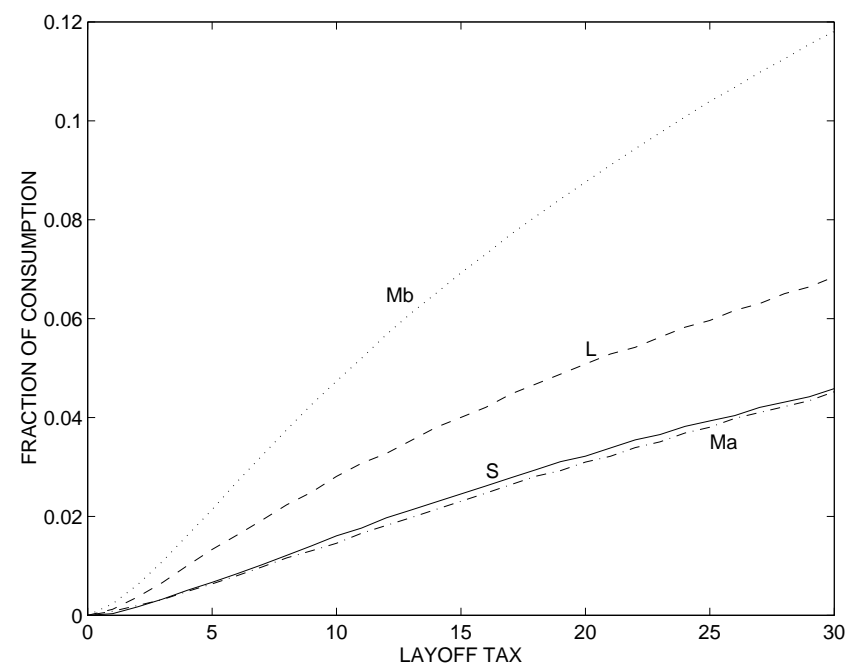

Figure 5. A job finder's welfare loss due to the presence of a layoff tax, computed as a fraction of per capita consumption at a zero layoff tax.

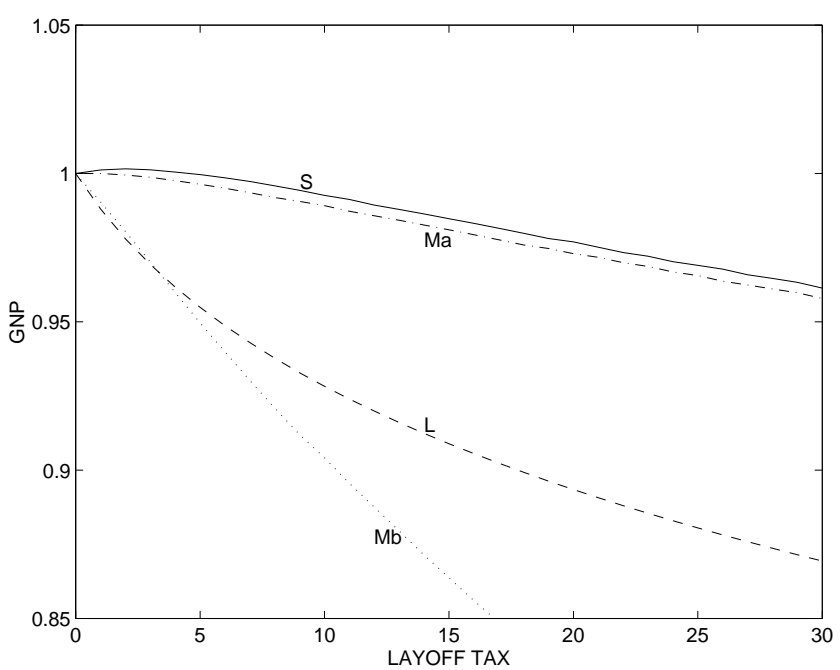

Figure 7. GNP index for different values of the layoff tax. The index is equal to one at a zero layoff tax.

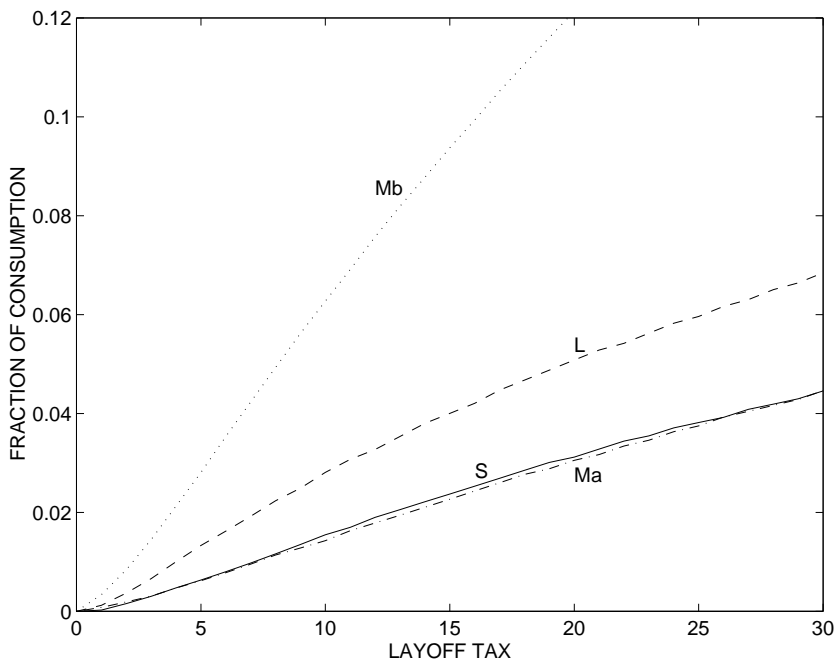

Figure 6. An unemployed worker's welfare loss due to the presence of a layoff tax, computed as a fraction of per capita consumption at a zero layoff tax.

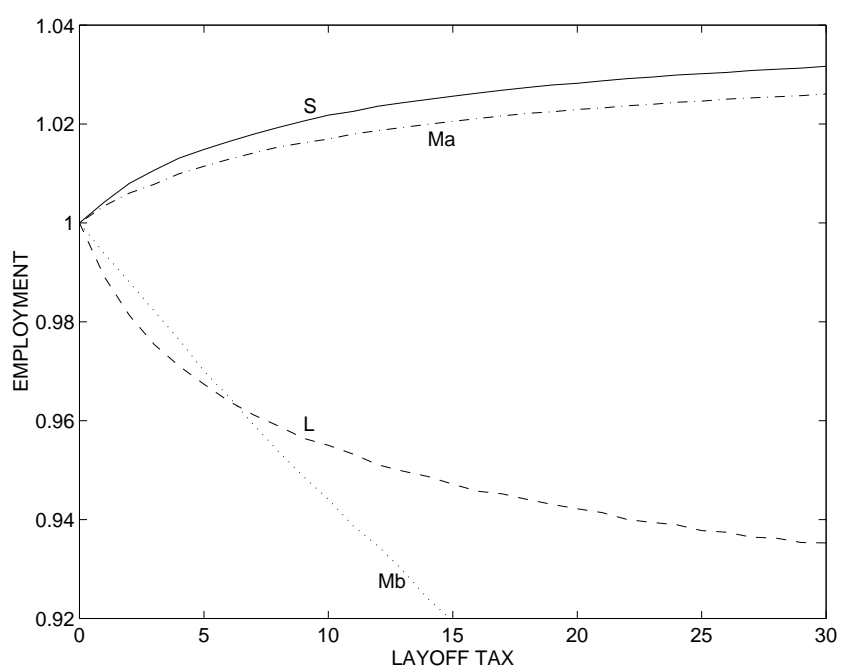

Figure 8. Employment index for different values of the layoff tax. The index is equal to one at a zero layoff tax. 


\subsection{Sensitivity Analysis}

To examine the sensitivity of the results to changes in the parameterization of the models, we have analyzed deviations of plus and minus 50 percent in all parameter values or, in some cases, deviations of plus and minus 50 percent in the relevant economic measures implied by the parameters. An example of the latter is the discount factor $\beta$ which is chosen to be 0.9985 in the baseline case, making the annual interest rate 4.0 percent. We analyze deviations in $\beta$ such that the annual interest rate is either 2.0 or 6.0 percent. In each sensitivity test of any one parameter, all other parameters are kept at their values in the benchmark calibration of section 4.1 .

Besides the discount factor, other parameters common to all models are varied as follows. The probability of drawing a new productivity level at work in the benchmark parameterization is such that a worker will on average draw a new productivity once a year. We examine deviations in this probability so that the average time between productivity draws is 0.5 or 1.5 years. The variance of the conditional distribution of new productivity levels is also decreased and increased by 50 percent relative to its benchmark value of 0.01 .

Concerning the search model, we study deviations of plus and minus 50 percent in each parameter of the functions $\gamma(s)$ and $\pi(s)$, i.e., the functions mapping search intensities into disutility of search and probabilities of obtaining a wage offer, respectively. The remaining parameter in the search model is the disutility of work $A_{s}$ which is equal to 0.5 in the benchmark case. We do examine a 50 percent reduction in this parameter but we only allow for an upper parameter value of 0.6 since a full 50 percent increase makes the disutility of work equal to the productivity of a new job which turns out to close down all economic activity. Except for this caveat which also applies to the matching framework, we analyze deviations of plus and minus 50 percent in all other parameters specific to the matching model, i.e., the cost of posting a vacancy and the parameters in the matching function and the Nash product.

Because of the recursive nature of the employment lottery model where the reservation productivity is computed before calculating the employment to population ratio, it turns out that the parameter value of the disutility of working does not affect the relative change in employment in response to a change in the layoff tax. But we do perform a sensitivity 
analysis with respect to the coefficient of relative risk aversion in consumption which is unity in the benchmark case of logarithmic utility. We examine a 50 percent increase and decrease in that coefficient for the utility function $u(c)=\left(c^{1-\eta}-1\right) /(1-\eta)$.

The results of the sensitivity analysis are reported in figures 9 through 12 . The layoff tax takes on three values, $\tau \in\{0,10,20\}$. Recall that $\tau=10$ and $\tau=20$ correspond roughly to half a year and one year of an average worker's output, respectively, in the benchmark calibration. Of course, this approximation may no longer hold for some of our sensitivity tests which all involve large perturbations in parameters. Each employment index is normalized to unity at a zero layoff tax for the particular parameterization considered. The solid line in a figure reproduces the benchmark result from figure 8 but here only for three values of the layoff tax.

Figures 9 through 12 show robustness of our earlier findings that a layoff tax is associated with higher employment in the search model and the matching model with a constant relative split of the match surplus, and lower employment in the other two models. To get a feel for the sensitivity analysis let us comment on a couple of outliers in the figures. The upper curve in figure 9 is obtained when picking a higher probability of drawing a new productivity level at work so that the average time between draws is cut by 50 percent to just half a year. At a zero layoff tax, this choice of parameter value yields the highest unemployment rate in the search model among all its parameterizations. This is because the frequent arrivals of new productivity levels spur a large amount of reallocation. This frictional unemployment is then found to fall relatively sharply when increasing the layoff tax, producing large increases in the employment index. The same argument is true for the matching model with a constant relative split of the match surplus where this parameter perturbation corresponds to one of the two highest curves in figure 10. Concerning the upper and the lower curve for the employment lottery model in figure 12 , these are obtained when setting the coefficient of relative risk aversion equal to 1.5 and 0.5 , relatively. A low risk aversion implies here also a higher willingness to substitute leisure for consumption which explains why employment plummets in response to a layoff tax that reduces the attractiveness of working. 


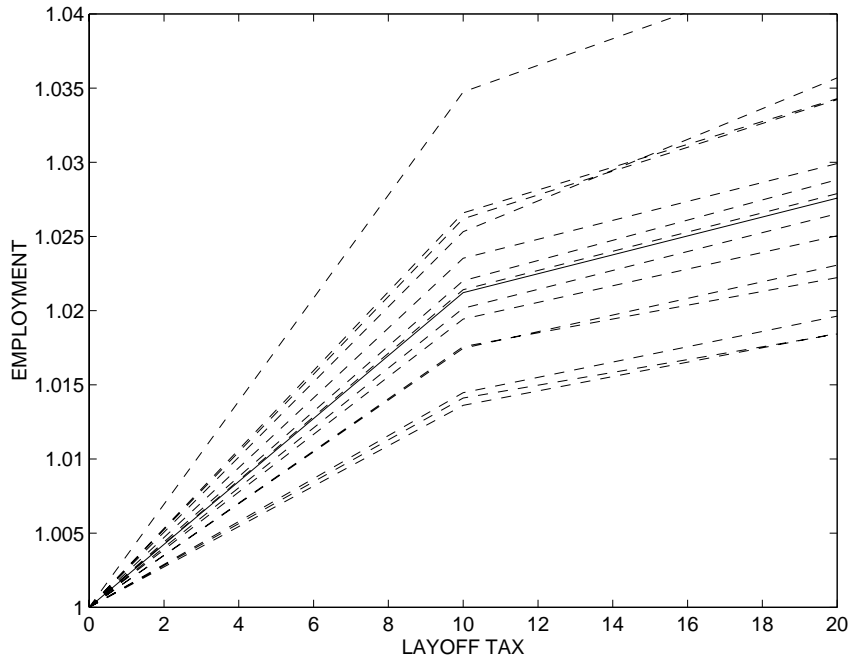

Figure 9. Sensitivity analysis of the employment index in the search model. The solid line is the benchmark parameterization. The layoff tax takes on three values, $\tau \in\{0,10,20\}$.

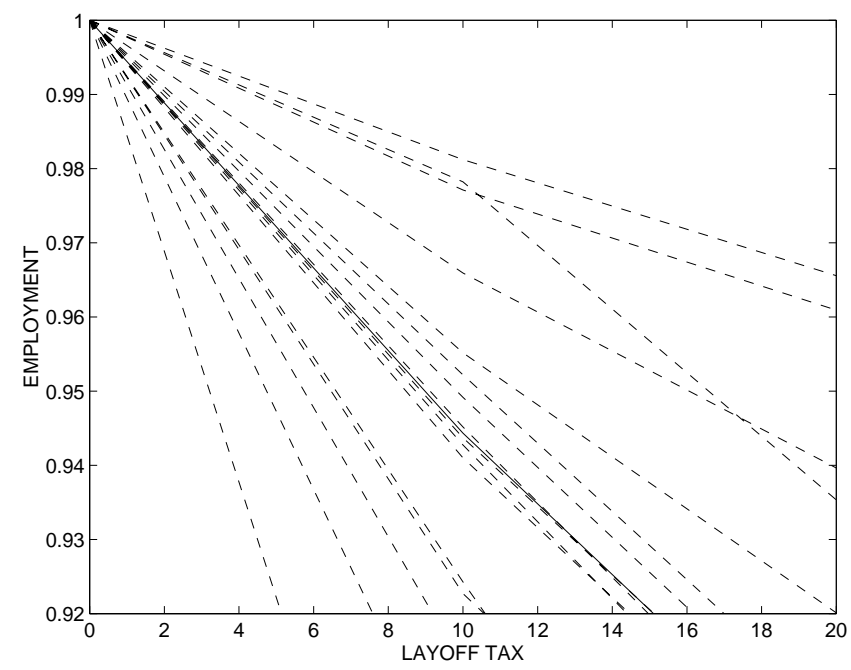

Figure 11. Sensitivity analysis of the employment index in the matching model when workers' relative share of the match surplus increases with the layoff tax. The solid line is the benchmark parameterization. The layoff tax takes on three values, $\tau \in\{0,10,20\}$.

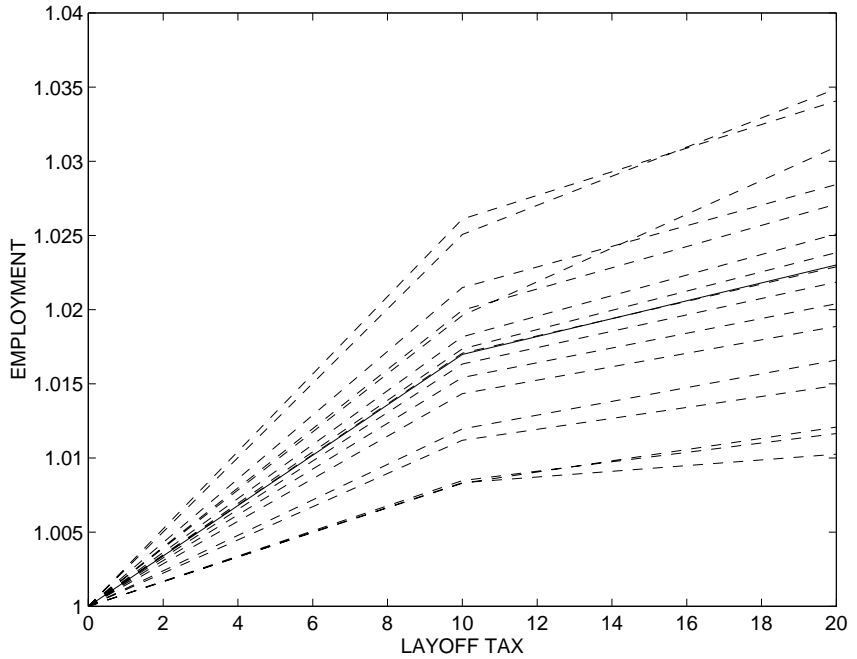

Figure 10. Sensitivity analysis of the employment index in the matching model with a constant relative split of the match surplus. The solid line is the benchmark parameterization. The layoff tax takes on three values, $\tau \in\{0,10,20\}$.

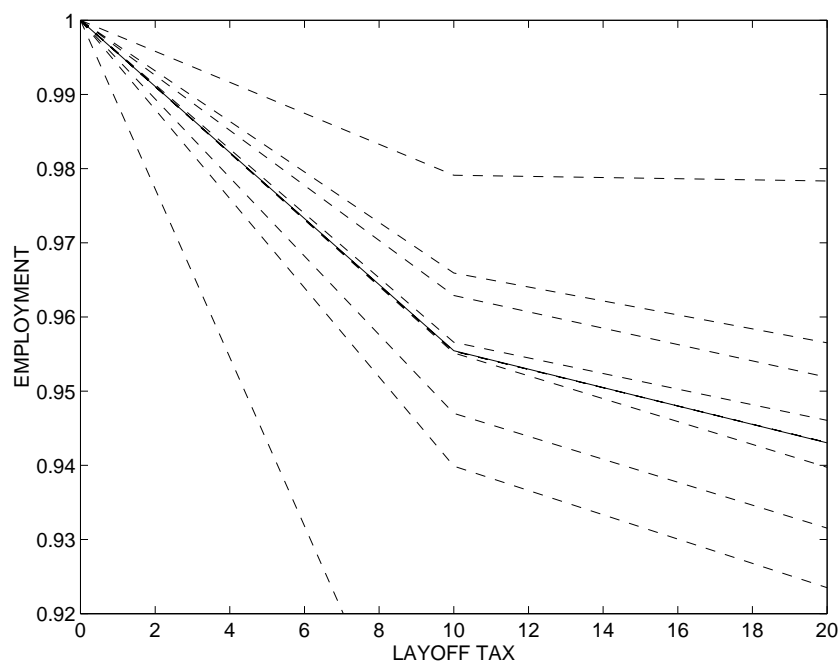

Figure 12. Sensitivity analysis of the employment index in the employment lottery model. The solid line is the benchmark parameterization. The layoff tax takes on three values, $\tau \in\{0,10,20\}$. 


\section{Economic Forces at Work}

\subsection{Search model}

The intuition for lower unemployment in the search model is quite straightforward. Layoff costs make it more costly to reallocate labor in response to productivity shocks. Fewer reallocations in the economy translates into less frictional unemployment and workers are "locked into" their jobs. Lower unemployment is thus attained at the cost of a less efficient labor allocation. The common argument that layoff costs will reduce the number of jobs in the economy does not apply for the following reason. Jobs are available in the search model as long as the unemployed have "reasonable" demands for compensation. Layoff costs will naturally reduce labor's earnings because of not only the layoff costs incurred in the production process but also the lower productivity associated with a less efficient labor allocation. However, workers who do accept necessary cuts in compensation will be working in the search model and they will on average enjoy longer job tenures as compared to an economy without layoff costs.

There is one qualification to the above description of the economic forces at work in the search model. The presence of layoff costs makes jobs less attractive, thus, the potential return to job search falls. This lower return causes unemployed workers to invest less in job search, i.e., they choose a lower search intensity. The reduced search intensity is reflected in figure 4 in form of a lower probability of finding a job within 10 weeks. ${ }^{5}$ If we fix the length of job tenures in the model, a lower search intensity would necessarily increase the economy's unemployment rate. As an illustration, consider the following alternative parameterization with two possible values of the productivity level on the job,

$$
p=\left(\begin{array}{c}
0 \\
.75
\end{array}\right) \quad \text { and } \quad \pi\left(p, p^{\prime}\right)=\left(\begin{array}{cc}
1 & 0 \\
.005 & .995
\end{array}\right)
$$

where the transition probabilities, $\pi\left(p, p^{\prime}\right)$, are chosen so that the equilibrium level of unemployment without layoff costs is roughly the same as in Section 4 . The parameterization has the implication that all jobs in an equilibrium are exogenously destroyed at

\footnotetext{
5 There would be still other effects on the probability of finding a job if we had assumed that unemployed workers draw a productivity from a distribution of productivities rather than one single possible value, $p^{\circ}$.
} 
the rate .005 , i.e., layoff costs cannot affect the length of job tenures. As a consequence, figure 13 shows how higher layoff costs which reduce workers' search intensity must necessarily increase unemployment. In the more general case, the final effect upon equilibrium unemployment depends on the relative importance of less diligent job search versus longer job tenures.

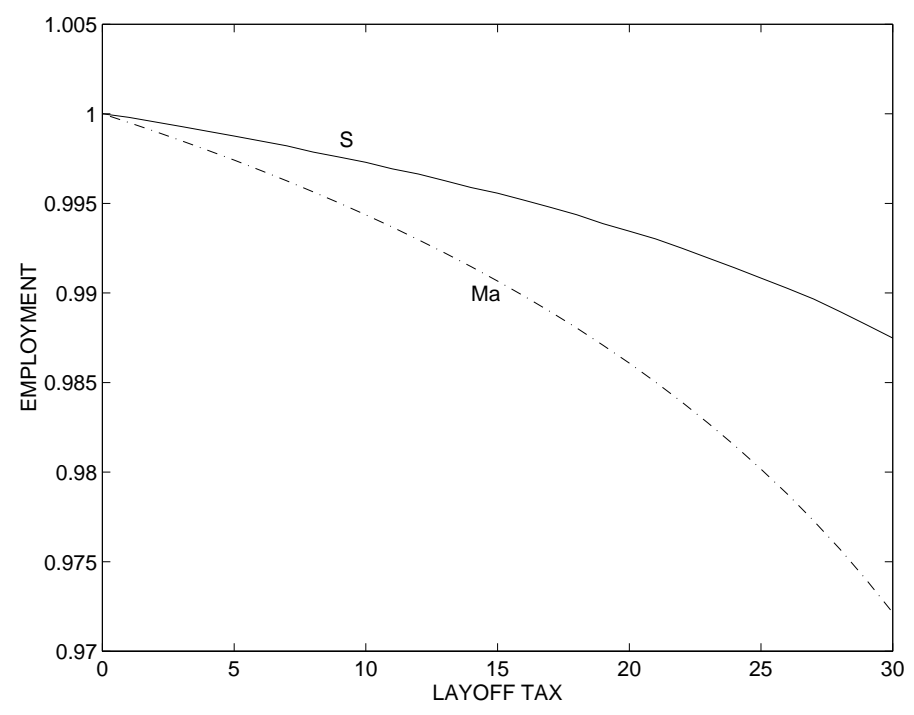

Figure 13. Employment index for different values of the layoff tax. The index is equal to one at a zero layoff tax. The parameterization is modified according to (16).

\subsection{Matching model}

Unemployment is also lower with layoff costs in the matching model with a constant relative split of the match surplus, as shown in figure 8. The explanation is once again that the costly reallocation of labor results in longer job tenures and lower frictional unemployment. But as before there exists an opposing effect that would necessarily increase the unemployment rate if the length of job tenures was exogenously given in our model. This time the opposing effect is not workers' search intensity falling in response to less attractive jobs but rather the impact of layoff costs on firms' ability to recover incurred vacancy costs. It is instructive to examine the break-even condition for new vacancies 
in (10.a). The left-hand side of (10.a) is the expected gain of posting a vacancy which is negatively affected by a higher layoff cost. In an equilibrium, the expected gain must be restored and be equal to the cost of posting a vacancy, $\kappa$. Market forces can attain this outcome in two ways; 1) a longer average job tenure (through a lower reservation productivity on the job) means that the expected discounted stream of surpluses from a consummated match, $Z\left(p^{\circ}\right)$, becomes larger; 2) a higher unemployment to vacancy ratio maps into a higher probability of filling a vacancy, $M(u, v) / v$, which also increases the expected gain of posting a vacancy. While longer job tenures tend to decrease unemployment, a higher probability of filling a vacancy (a higher unemployment to vacancy ratio) may be associated with a higher absolute level of unemployment. In the special case when the length of job tenures is exogenously given, higher layoff costs will unambiguously raise both the unemployment to vacancy ratio and the level of unemployment, as shown by Burda (1992). Our matching model with the parameterization in (16) inherits those same properties, and the employment effects are depicted in figure 13.

The alternative specification of the matching model where workers' relative share of the match surplus increases with the layoff cost has dramatically different employment implications. Employment in figure 8 is seen to plummet in response to higher layoff costs. The equilibrium condition that firms finance incurred vacancy costs with retained earnings from the matches becomes exceedingly difficult to satisfy when a higher layoff cost erodes the fraction of match surpluses going to firms. Firms can only break even if the expected time to fill a vacancy is cut dramatically, i.e., there has to be a large number of unemployed workers for each posted vacancy. This equilibrium outcome is reflected in the very low probability of a worker finding a job within 10 weeks in figure $4 .^{6}$

But there is also a qualification to the economic forces at work in the matching model where workers' relative share of the match surplus increases with the layoff cost. The model has the same opposing effects on the equilibrium unemployment rate as in the matching model with a constant relative split of the match surplus. We can therefore find

\footnotetext{
6 It is worth noting that every worker faces the same probability of finding a job regardless of past experience including the length of the current unemployment spell. The model assumes that all the unemployed serve as a reserve of workers capable and willing to fill posted vacancies.
} 
a parameterization for which higher layoff costs can actually reduce the unemployment rate due to an endogenous large increase in the length of job tenures that outweighs the decline in the firms' share of the match surplus. Such an example is as follows,

$$
p=\left(\begin{array}{c}
0 \\
.70 \\
.75
\end{array}\right) \quad \text { and } \quad \pi\left(p, p^{\prime}\right)=\left(\begin{array}{ccc}
1 & 0 & 0 \\
.0005 & .9995 & 0 \\
0 & .005 & .995
\end{array}\right)
$$

Parameterization (17) is similar to (16), we have just included an additional intermediate state with $p=.70$. It turns out that the economy will not operate at this productivity level when there are no layoff costs, so the rate of job destruction will then be .005 . However, if the layoff cost reaches a critical value of 3 , the economy's reservation productivity drops down to .70 and figure 14 displays a sharp increase in employment. The fact that firms are now retaining workers with productivity .70 means that the job destruction rate has fallen by a factor of 10 from .005 to .0005 .

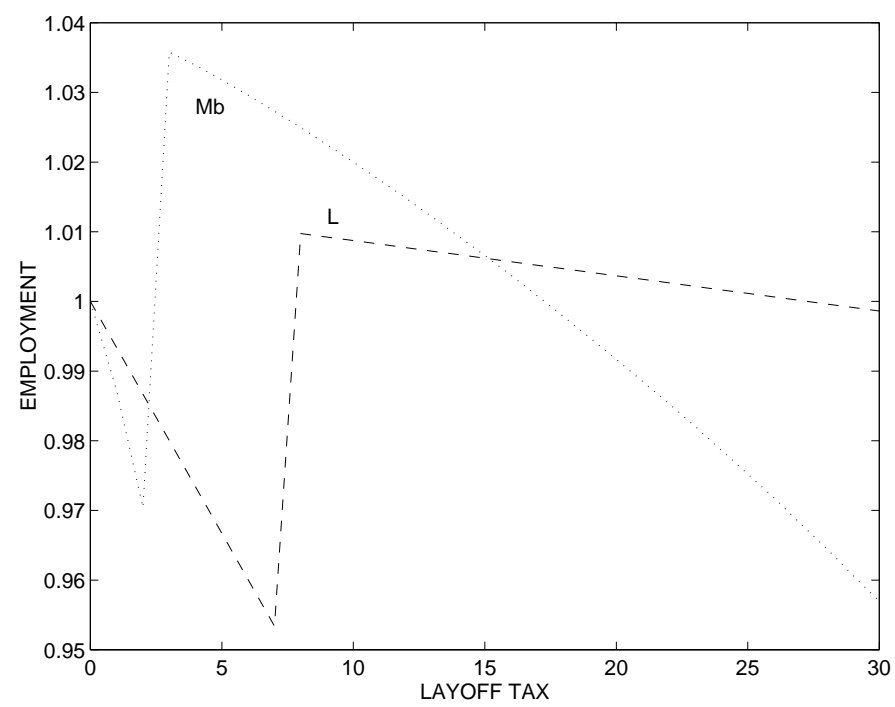

Figure 14. Employment index for different values of the layoff tax. The index is equal to one at a zero layoff tax. The parameterization is modified according to $(17)$. 


\subsection{Model with employment lotteries}

As in Hopenhayn and Rogerson (1993), the model with employment lotteries delivers the result that employment decreases with a higher layoff cost. In general, a higher layoff cost is synonymous from a private perspective to a deterioration in the production technology, the optimal change in the workers' employment lotteries will therefore depend on the strength of the substitution effect versus the income effect. Loosely speaking, the first-order impact of the income effect is eliminated by the government lump-sum transfer of the layoff tax revenues back to the private economy. Thus, layoff costs in models with employment lotteries have strong negative employment implications caused by substitution away from consumption towards leisure.

In the special case of logarithmic preferences used by Hopenhayn and Rogerson, the optimal choice of employment in (15) is given by

$$
N^{*}=\frac{1}{A_{l}}-\frac{T+\Pi}{w^{*}} .
$$

The precise employment effect is here driven by profit flows from firms gross of layoff taxes expressed in terms of the wage rate. Since these profits are to a large extent generated in order to pay for firms' future layoff taxes, a higher layoff tax tends to increase the accumulation of such funds with a corresponding negative effect on the optimal choice of employment. However, it is conceivable that the peculiar parameterization in (17) might overturn the monotonicity of profit flows when the reservation productivity suddenly falls from 0.75 to 0.70 with a dramatic reduction in the layoff incidence by a factor of 10 . This conjecture is confirmed in figure 14 where employment increases when moving from a layoff tax of 7 to 8 .

To summarize, it takes fairly extreme parameterizations to overturn the negative employment implications of layoff taxes in models of employment lotteries. The first-order effect in these models is that agents substitute away from consumption towards leisure by reducing the probability of working in the lotteries. 


\section{Concluding Comments}

What does general equilibrium analysis tell us about the effects of layoff costs? This paper sheds light on the implications of three dominant frameworks of employment determination; search models, matching models and models with employment lotteries. The predictions of these various frameworks are shown to be the same in a number of economic dimensions. For example, layoff costs do reduce the reservation productivity in layoff decisions and thereby diminish the incidence of layoffs. The cost of doing so manifests in a less efficient allocation of labor. Despite these common implications, the models provide diametrically different answers to how layoff costs affect employment. Our bare-bones versions of the models help us to understand their contradictory conclusions.

Models with employment lotteries predict that employment should fall in response to layoff costs. Since these costs reduce the private returns to working, agents choose a lower probability of working in favor of more stochastic leisure which can be accomplished at a small material cost because of the collective sharing of aggregate consumption. Thus, the driving force in models with employment lotteries is their well-known high elasticity of labor supply. In contrast, search models predict that layoff costs should be associated with lower unemployment. This result is driven by the fact mentioned above that layoff costs reduce the amount of labor reallocation. In other words, layoff costs reduce frictional unemployment in search models at the cost of a less efficient labor allocation. Agents enjoy longer job tenures in exchange for lower average pay.

Note that the disparate employment effects of layoff costs in the two models are driven by forces that are present in both frameworks. Layoff costs also reduce labor turnover in models with employment lotteries but since these models have no frictional unemployment, the central causation of search models is absent. Layoff costs also make working less attractive in search models but here there are no negative employment effects associated with indivisibilities in individual labor supply. Such indivisibilities are inconsequential under the assumption of risk neutrality or, in the case of risk aversion, search models typically assume incomplete market structures that do not allow for employment lotteries.

Matching models with a constant relative split of the match surplus between firms and workers predict that layoff costs have positive employment effects. As in search models, 
the explanation is that workers are "locked into" their current employment and there is little reallocation of labor. But this employment effect is overturned when adopting the assumption that the workers' relative share of the match surplus increases with layoff costs. The equilibrium condition that firms finance incurred vacancy costs with retained earnings from the matches becomes difficult to satisfy when higher layoff costs erode the fraction of match surpluses going to firms. The equilibrium unemployment rate must therefore rise to reduce the expected time and cost for firms to fill vacancies, and to weaken workers' bargaining position by lenghtening average unemployment spells. 


\section{Appendix}

We here demonstrate that the Mortensen and Pissarides' (1997) analysis of a two-tier wage system have the same implications as a model with Nash product (7.a). The only difference between the two formulations is that the wage in the Mortensen and Pissarides' setting is reduced in the first period by the worker's share of any future layoff tax, and future wages are increased by an amount equal to the net interest on this posted 'bond.'

The wage function associated with Nash product (7.a) is obtained from (11) and (8.a),

$$
\begin{aligned}
w(p) & =p-F(p)+\beta \int F\left(p^{\prime}\right) d G\left(p, p^{\prime}\right) \\
& =p-(1-\delta) Z(p)+\beta \int(1-\delta) Z\left(p^{\prime}\right) d G\left(p, p^{\prime}\right)
\end{aligned}
$$

Mortensen and Pissarides' Nash product in the first period of employment is

$$
\left(W_{1}(p)-Z_{u}\right)^{\delta} F_{1}(p)^{1-\delta}
$$

while the Nash product for future periods of negotiations in a continuing match is

$$
\left(W_{+}(p)-Z_{u}\right)^{\delta}\left(F_{+}(p)+\tau\right)^{1-\delta}
$$

The solutions to the maximization of these Nash products are

$$
\begin{aligned}
W_{1}(p)-Z_{u} & =\delta Z(p), \\
F_{1}(p) & =(1-\delta) Z(p), \\
W_{+}(p)-Z_{u} & =\delta(Z(p)+\tau), \\
F_{+}(p) & =(1-\delta) Z(p)-\delta \tau,
\end{aligned}
$$

where we conjecture that the match surplus $Z(p)$ is the same as in (18). The associated wage functions can be written as

$$
\begin{aligned}
& w_{1}(p)=p-F_{1}(p)+\beta \int F_{+}\left(p^{\prime}\right) d G\left(p, p^{\prime}\right)=w(p)-\beta \delta \tau, \\
& w_{+}(p)=p-F_{+}(p)+\beta \int F_{+}\left(p^{\prime}\right) d G\left(p, p^{\prime}\right)=w(p)+r \beta \delta \tau,
\end{aligned}
$$

where the second equalities follow from (18) and (19), and $r \equiv \beta^{-1}-1$. 
Given the conjecture that the match surplus $Z(p)$ is identical for the two models, we have shown that the present value of a worker's total compensation for any completed job is the same across models which in turn implies the same present value of a firm's payoffs. It then follows that the two models share the same equilibrium allocation of labor in spite of the different bargaining formulations. 


\section{References}

Alvarez, Fernando and Marcelo Veracierto (1997) "Welfare Effects of Job Security Provisions under Imperfect Insurance Markets," manuscript, University of Chicago.

Bentolila, Samuel and Giuseppe Bertola (1990) "Firing Costs and Labour Demand: How Bad is Eurosclerosis?," Review of Economic Studies, 57, 381-402.

Bertola, Giuseppe (1990) "Job Security, Employment and Wages," European Economic Review, 34, 851-879.

Burda, Michael C. (1992) "A Note on Firing Costs and Severance Benefits in Equilibrium Unemployment," Scandinavian Journal of Economics, 94, 479-489.

Diamond, Peter A. (1982) "Wage Determination and Efficiency in Search Equilibrium," Review of Economic Studies, 49, 217-227.

Emerson, Michael (1988) "Regulation or Deregulation of the Labour Market: Policy Regimes for the Recruitment and Dismissal of Employees in the Industrialized Countries," European Economic Review, 32, 777-817.

Hansen, Gary D. (1985) "Indivisible Labor and the Business Cycle," Journal of Monetary Economics, 16, 309-327.

Hopenhayn, Hugo and Richard Rogerson (1993) "Job Turnover and Policy Evaluation: A General Equilibrium Analysis," Journal of Political Economy, 101, 915-938.

Hosios, Arthur J. (1990) "On the Efficiency of Matching and Related Models of Search and Unemployment," Review of Economic Studies, 57, 279-298.

Lazear, Edward P. (1990) "Job Security Provisions and Employment," Quarterly Journal of Economics, 105, 699-726.

Ljungqvist, Lars and Thomas J. Sargent (1998) "The European Unemployment Dilemma," Journal of Political Economy, 106, 514-550.

McCall, John J. (1970) "Economics of Information and Job Search," Quarterly Journal of Economics, 84, 113-126.

Mortensen, Dale T. (1982) "The Matching Process as a Non-Cooperative Bargaining Game," in The Economics of Information and Uncertainty, ed. J.J. McCall. Chicago: University of Chicago Press for the National Bureau of Economic Research. 
Mortensen, Dale T. and Christopher A. Pissarides (1997) "New Developments in Models of Search in the Labor Market," manuscript to be published in Handbook of Labor Economics.

OECD (1994) "The OECD Jobs Study: Evidence and Explanations," Paris.

Pissarides, Christopher (1985) "Taxes, Subsidies, and Equilibrium Unemployment," Review of Economic Studies, 52, 121-133.

Rogerson, Richard (1988) "Indivisible Labor, Lotteries, and Equilibrium," Journal of Monetary Economics, 21, 3-16.

Saint-Paul, Gilles (1995) "The High Unemployment Trap," Quarterly Journal of Economics, 110, 527-550.

Stigler, George J. (1961) "The Economics of Information," Journal of Political Economy, 69, 213-225. 